\title{
ISO 9126 UNTUK PENGUJIAN GAME EDUKASI MEMBUANG SAMPAH BERBASIS ANDROID
}

\author{
Silvia Ratna ${ }^{1)}$ \\ ${ }^{I}$ Teknik Informatika, Fakultas Teknologi Informasi Universitas Islam Kalimantan Muhammad Arsyad Al Banjari \\ Banjarmasin \\ Email: via.borneo@gmail.com
}

\begin{abstract}
Games are applications that are familiar to people from all walks of life. Efforts to increase the efficiency of providing applications that contain educational elements require a variety of alternatives and new innovations in programming to be applied as a tool to simplify the learning process. This study aims to create a game design called the game "Throw your trash" by inserting educational elements about how to dispose of garbage in its place and introducing the types of waste. And the sample used is elementary school students, because of their interest in the theoretical learning process, considering that children prefer to play games. The methodology used is starting from system analysis, design and implementation stages, and testing using ISO 9126.The results of this educational game to throw garbage show that the game application based on the aspect obtained a percentage of $95 \%$ of the Functionality test and the results of the analysis of usability testing obtained a percentage of $81.89 \%$
\end{abstract}

Kata Kunci: education, games, testing, android, ISO 9126

\section{PENDAHULUAN}

Limbah sampah adalah residu padat yang dihasilkan oleh aktivitas manusia setiap harinya dan/atau alam berdasarkan Undang-Undang Pengelolaan Sampah No. 18 tahun 2008. Limbah lingkungan memiliki dua komponen yang saling terkait; Misalnya spesies dan lingkungan akan mempengaruhi keadaan yang masih timpang pada satu hal. Diproyeksikan Indonesia akan memproduksi sampah 64 juta ton/tahun. Melihat data Kementerian Lingkungan Hidup dan Kehutanan (KLHK), sampah organik menyumbang 60\% keseluruhan sampah merupakan komponen sampah yang dominan. Urutan kedua adalah sampah plastik $14 \%$, diikuti sampah kertas 9\% dan karet 5,5\%. Baja, kain, kaca dan bentuk limbah lainnya adalah limbah lainnya (Qodriyatun, 2014). Dilema limbah semakin tak terelakkan saat ini. Jika dibiarkan, itu akan menjadi lebih rumit. Pembubaran sampah mengganggu pandangan sehingga menghalangi aliran air dan lambat laun menyebabkan banjir. Isu sampah yang dinamis akibat peningkatan jumlah sampah tidak dibarengi dengan perubahan dan perbaikan instalasi dan infrastruktur pengelolaan sampah. Bayangkan apa yang akan terjadi dalam 20 tahun mendatang; mungkin planet ini akan penuh dengan limbah dan banyak kerusakan limbah. Pendidikan tentang sampah seharusnya diajarkan ke setiap orang untuk membuang sampah semuda mungkin, sehingga anak memiliki minat lingkungan yang lebih besar.

Kita tahu bagaimana keadaan saat ini karena banyak anak tidak peduli dengan yang mereka perbuat, termasuk membuang sampah sembarangan. Pengaruh lain seperti masih minimnya orang tua yang mendidik anaknya membuang sampah juga berpengaruh. Game pembelajaran merupakan salah satu genre yang digunakan untuk memberikan kesadaran konsumen dengan menggunakan media yang spesifik dan menarik. (Nurrun Muchammad, 2013). Menurut Edward, permainan edukatif memiliki banyak efek menguntungkan pada penerapannya, termasuk:

1. Orang-orang menggunakan game secara ekstensif di perguruan tinggi, industri, dan keterampilan militer

2. Studi Murphy dan teman-temannya pada tahun 2002 telah menunjukkan bahwa permainan secara efisien dilakukan untuk 
mengasah skill matematika dan membaca pada anak-anak

3. Studi Lieberman pada tahun 1997 dan McPhershon dan kawan-kawan pada tahun 2006 telah menunjukkan dukungan bagi anakanak penderita asma dan diabetes untuk mengelola kebiasaan hidup yang lebih sehat.

Ini adalah jenis permainan yang serius. Dunia game mengambil bentuk lingkungan sehari-hari. Area di sekitar tempat tinggal adalah posisi yang digunakan dalam permainan ini. Para orang tua hendaknya melancarkan edukasi kepada anaknya tentang pentingnya menjaga kebersihan lingkungan karena lingkungan keluarganya. Game menangkap sampah yang berjatuhan adalah cerita dari game ini, pemain dapat memilih jenis sampah terlebih dahulu sebelum bermain, seperti daun kering, buah busuk, dan makanan sisa yang basi, sedangkan sampah anorganik yaitu botol plastik air mineral, pecahan kaca, dan plastik bekas. Semakin banyak sampah dikumpulkan, semakin besar manfaat yang didapat pengguna.

Sebelum dilakukan pengujian terhadap dampak penggunaan permainan game edukasi sampah, maka akan dilakukan uji berdasarkan kualitas sebuah perangkat lunak. Sistem yang diusulkan diuji dengan standar ISO 9126 dimana meliputi functionality, efficiency, reliability, dan usability. ISO 9126 dipilih karena merupakan standar kualitas internasional yang sudah teruji validitas dan reliabilitasnya (Sari, 2016).

Berdasarkan uraian masalah diatas, maka penulis mengusulkan pengujian dengan judul "ISO 9126 Untuk Pengujian Game Edukasi Membuang Sampah berbasis Android" dengan memilih pengujian functionality dan usability karena perangkat lunak yang digunakan adalah berbentuk game.

\section{METODE PENELITIAN}

Pendekatan penelitian ini didasarkan pada model perangkat lunak model waterfall yang melewati beberapa tingkatan yaitu (Irwanto, 2021):

1. Tahap analisis sistem

2. Tahap perancangan dan implementasi
3. Tahap pengujian

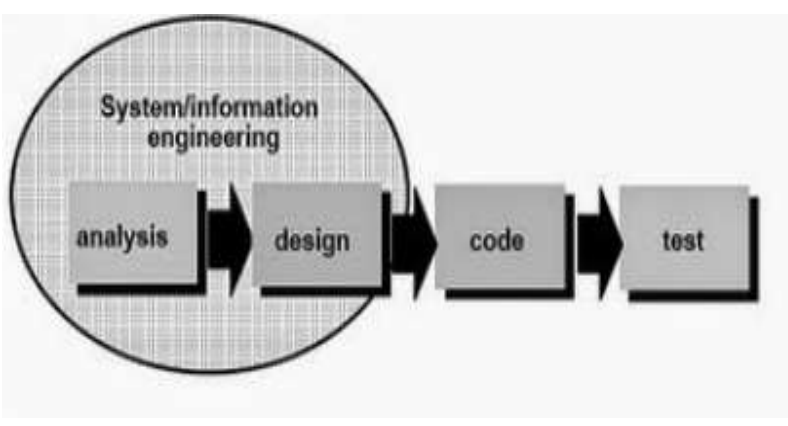

Gambar 1. Model Waterfall

Langkah-langkah berikut diambil untuk menyelesaikan penelitian:

1. Analisa sistem

Pada tahap ini dilakukan analisis masalah dan kekurangan masalah sistem berdasarkan fenomena pengujian dan spesifikasi sistem.

2. Perancangan dan implementasi sistem

Implementasi dilakukan sesuai dengan hasil analisis sistem, kemudian hasil analisis dan desain diintegrasikan ke dalam sistem.

3. Pengujian

Sistem diuji menggunakan standar ISO 9126 sesuai dengan tujuan pengujian karena pada sistem informasi yang akan diuji kemudian diberikan berbagai rangkaian pengujian kualitas perangkat lunak yang menggunakan beberapa instrumen penelitian sesuai standar ISO 9126 yaitu functionality dan usability

\section{HASIL DAN PEMBAHASAN}

a. Tahap perancangan

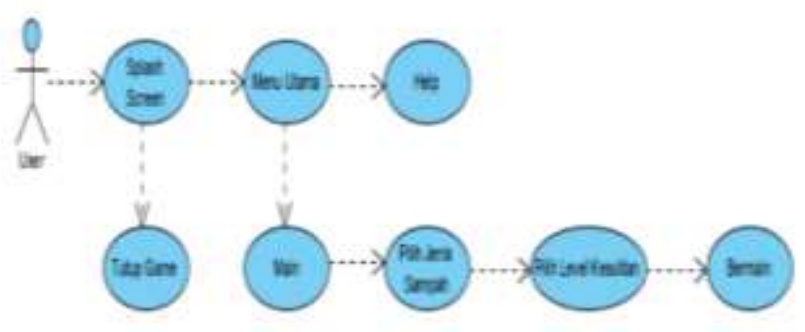

Gambar 2. Use case 
Pertama kali user akan masuk game, user akan masuk halaman utama yang berisi tombol main. Setelah user menekan tombol main, maka halaman selanjutnya yaitu memilih jenis sampah (organik atau anorganik), dan jenis kesulitan (mudah, sedang, sulit). Sistem membawa Anda ke halaman game saat dipilih. Pengguna harus mengumpulkan hal-hal yang berbeda tergantung pada bentuk sampah di daftar ini. Di sini pengguna diberi jumlah sampah maksimal dalam 100 detik. Setiap pemborosan akan dihitung sebelum waktunya habis. Tantangan pengguna adalah waktu dan item bom yang tidak boleh ditangkap. Jika waktu hampir habis, pengguna ditampilkan selesai mengumpulkan sampah. Selain itu, skor akan turun jika pengguna menangkap objek ledakan.

\section{b. Tahap Implementasi}

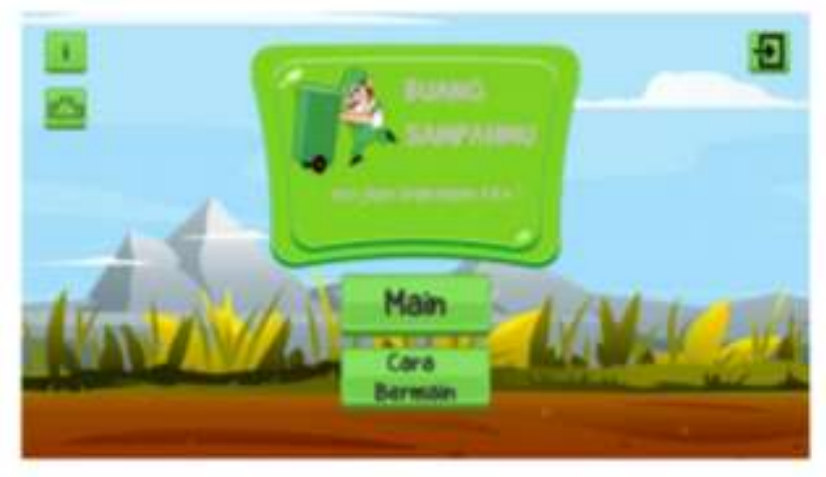

Gambar 3 Halaman utama

\section{c. Tahap Pengujian}

Selama tahap pengujian ini, serangkaian pengujian jaminan kualitas perangkat lunak dengan menggunakan berbagai alat analisis sesuai dengan pedoman ISO 9126 akan dilakukan. Penilaian perangkat ini dilakukan dengan rentang usia 10 hingga 30 tahun, terutama terkait Usability dan Functionality.

Hasil Pengujian Functionality (Tabel 1) dengan jumlah Responden 83 Orang. Desain pengujian Functionality disesuaikan dengan desain perangkat lunak yang akan diuji, yang berhubungan fungsi - fungsi standar penggunaan perangkat lunak tersebut (Triyadi, 2020).
Tabel 1. Pengujian Functionality

\begin{tabular}{|c|c|c|c|}
\hline No & Pertanyaan & $\mathrm{Ya}$ & Tidak \\
\hline 1 & $\begin{array}{l}\text { Apakah fungsi tombol } \\
\text { info sudah berfungsi } \\
\text { dengan benar? }\end{array}$ & 72 & 11 \\
\hline 2 & $\begin{array}{l}\text { Apakah fungsi tombol } \\
\text { menampilkan highscore } \\
\text { sudah berfungsi dengan } \\
\text { benar? }\end{array}$ & 80 & 3 \\
\hline 3 & $\begin{array}{l}\text { Apakah fungsi tombol } \\
\text { cara bermain berfungsi } \\
\text { dengan benar? }\end{array}$ & 81 & 2 \\
\hline 4 & $\begin{array}{l}\text { Apakah halaman menu } \\
\text { utama pada tombol main } \\
\text { berfungsi dengan benar? }\end{array}$ & 82 & 1 \\
\hline 5 & $\begin{array}{l}\text { Apakah pilihan "sampah } \\
\text { organik" untuk memulai } \\
\text { permainan berfungsi } \\
\text { dengan benar? }\end{array}$ & 80 & 3 \\
\hline 6 & $\begin{array}{l}\text { Apakah pilihan "sampah } \\
\text { anorganik" untuk } \\
\text { memulai permainan } \\
\text { berfungsi dengan benar? }\end{array}$ & 80 & 3 \\
\hline 7 & $\begin{array}{l}\text { Apakah pilihan tingkat } \\
\text { kecepatan lambat } \\
\text { berfungsi dengan benar? }\end{array}$ & 74 & 9 \\
\hline 8 & $\begin{array}{l}\text { Apakah pilihan tingkat } \\
\text { kecepatan sedang } \\
\text { berfungsi dengan benar? }\end{array}$ & 79 & 4 \\
\hline 9 & $\begin{array}{l}\text { Apakah pilihan tingkat } \\
\text { kecepatan sulit berfungsi } \\
\text { dengan benar? }\end{array}$ & 78 & 5 \\
\hline 10 & $\begin{array}{l}\text { Apakah tampilan pesan } \\
\text { yang disampaikan sesuai } \\
\text { atau berfungsi dengan } \\
\text { benar? }\end{array}$ & 80 & 3 \\
\hline 11 & $\begin{array}{l}\text { Apakah tombol "main } \\
\text { lagi" berfungsi dengan } \\
\text { benar? }\end{array}$ & 81 & 2 \\
\hline 12 & $\begin{array}{l}\text { Apakah tombol kembali } \\
\text { berfungsi dengan benar? }\end{array}$ & 78 & 5 \\
\hline 13 & $\begin{array}{l}\text { Apakah penilaian skor } \\
\text { berfungsi dengan benar }\end{array}$ & 79 & 4 \\
\hline & Total & 1024 & 55 \\
\hline
\end{tabular}


Tabel 2. Skor Max Functionality

\begin{tabular}{ccc}
\hline Pertanyaan & Skor Total & Skor Maksimum \\
\hline 1 & 72 & 83 \\
2 & 80 & 83 \\
3 & 81 & 83 \\
4 & 82 & 83 \\
5 & 80 & 83 \\
6 & 80 & 83 \\
7 & 74 & 83 \\
8 & 79 & 83 \\
9 & 78 & 83 \\
10 & 80 & 83 \\
11 & 81 & 83 \\
12 & 78 & 83 \\
13 & 79 & 83 \\
\hline Total & 1024 & 1079 \\
\hline
\end{tabular}

Dari hasil diatas dapat diketahui persentase untuk masing-masing penilaian, yaitu

$\begin{array}{lll}\text { Ya } & 0,949026877 \times 100 \% & 0,95 \\ \text { Tidak } & 0,050973123 \times 100 \% & 0,05\end{array}$

Analisis Data Pengujian Functionality

$$
0,949026877 \times 100 \%=95 \%
$$

Persentase 95 persen dari uji fungsionalitas dihasilkan berdasarkan analisis deskriptif dan perhitungan. Standar produk untuk Functionality didasarkan pada karakter Functionality dan memiliki skala yang baik dari skor persentase yang diterima.

Analisis Data Pengujian Usability

$$
0,819879518 \times 100 \% \quad 81.98 \%
$$

Angka tersebut adalah $81,98 \%$ berdasarkan hasil evaluasi Usability. Ini berada dalam kisaran yang layak dari peringkat ini untuk aplikasi dasar.

\begin{tabular}{|c|c|c|c|c|c|}
\hline & Pertanyaan & TS & KS & $\mathrm{S}$ & SS \\
\hline 1 & $\begin{array}{l}\text { saya tidak kebingungan } \\
\text { saat pertama kali bermain } \\
\text { permainan }\end{array}$ & 5 & 9 & 19 & 50 \\
\hline 2 & $\begin{array}{l}\text { kemudahan dalam } \\
\text { memahami permainan }\end{array}$ & 0 & 5 & 22 & 56 \\
\hline 3 & $\begin{array}{l}\text { kemudahan dalam } \\
\text { mempelajari permainan }\end{array}$ & 0 & 6 & 24 & 53 \\
\hline 4 & $\begin{array}{l}\text { permainan memberikan } \\
\text { informasi yang mudah } \\
\text { dipahami }\end{array}$ & 0 & 11 & 20 & 52 \\
\hline 5 & $\begin{array}{l}\text { saya mempelajari } \\
\text { permainan dengan cepat }\end{array}$ & 0 & 6 & 24 & 53 \\
\hline 6 & $\begin{array}{l}\text { permainan mudah } \\
\text { dimainkan }\end{array}$ & 0 & 4 & 21 & 58 \\
\hline 7 & $\begin{array}{l}\text { saya bisa mengatasi } \\
\text { kendala dengan mudah } \\
\text { dan cepat }\end{array}$ & 0 & 9 & 31 & 43 \\
\hline 8 & $\begin{array}{l}\text { saya bisa mengingat } \\
\text { bagaimana } \\
\text { mengoperasikan } \\
\text { permainan }\end{array}$ & 0 & 3 & 24 & 56 \\
\hline 9 & grafik permainan bagus & 3 & 14 & 26 & 40 \\
\hline 10 & $\begin{array}{l}\text { tampilan permainan } \\
\text { dengan objek gambar yang } \\
\text { menarik }\end{array}$ & 4 & 10 & 31 & 38 \\
\hline & Total & 12 & 77 & & \\
\hline
\end{tabular}

Tabel 3. Pengujian Usability

Tabel 4. Analisis Pengujian Usability

\begin{tabular}{ccc}
\hline Pertanyaan & Skor Total & Skor Maksimum \\
\hline 1 & 257 & 332 \\
2 & 290 & 332 \\
3 & 284 & 332 \\
4 & 268 & 332 \\
5 & 284 & 332 \\
6 & 295 & 332 \\
7 & 265 & 332 \\
8 & 296 & 332 \\
9 & 238 & 332 \\
10 & 245 & 332 \\
\hline Total & 2722 & 3320 \\
\hline
\end{tabular}




\section{KESIMPULAN DAN SARAN}

\section{Kesimpulan}

Berdasarkan tes dan hasil tes dengan 83 responden, dapat disimpulkan bahwa:

1. Dari titik fungsionalitas pengujian perangkat lunak, ini termasuk dalam kelas produk yang berhasil, pada tingkat 95 persen.

2. Hasil pengujian mencapai angka 81,98 persen dalam hal kegunaan. Ini berada dalam kisaran yang layak dari peringkat ini untuk aplikasi dasar.

\section{Saran}

1. Masih standar, interface masih bisa di kembangkan agar tidak monoton

2. Sistem hasil pencarian bisa dikembangkan lagi dengan menambahkan gambar 3D agar lebih menarik

3. Bisa dilanjutkan menjadi game online

\section{DAFTAR PUSTAKA}

Irwanto, I. (2021). Perancangan Media Game Edukasi Untuk Mata Pelajaran Fisika Dengan Menggunakan Model Waterfall Di Smk Negeri 2 Kota Serang. Jurnal Inovasi Penelitian, 1(11), 2311-2322.

Nurrun Muchammad Shiddieqy Hadna, (2013). "Pembuatan Game Honey Mars Menggunakan Unity 3d." Stmik Amikom, Yogyakarta

Qodriyatun, S. N. (2014). Meningkatkan Kesejahteraan Masyarakat Melalui Pengelolaan Sampah Berdasarkan Uu No. 18 Tahun 2008. Aspirasi: Jurnal MasalahMasalah Sosial, 5(1), 21-33.

Sari, T. N. (2016). Analisis Kualitas Dan Pengembangan Sistem Informasi Akademik Berbasis Web Menggunakan Standard Iso 9126. Jiko (Jurnal Informatika Dan Komputer), 1(1).

Triyadi, T. (2020). Aplikasi Monitoring Server Dan Analisis Kualitas Menggunakan Model Iso 